\title{
Art as an Investment and the Underperformance of Masterpieces
}

\author{
Jiangping Mei \\ Michael Moses ${ }^{1}$
}

August 2001

\begin{abstract}
This paper constructs a new data set of repeated sales of artworks and estimates an annual index of art prices for the period 1875-2000. Contrary to earlier studies, we find art outperforms fixed income securities as an investment, though it significantly under-performs stocks in the US. Art is also found to have lower volatility and lower correlation with other assets, making it more attractive for portfolio diversification than discovered in earlier research. There is strong evidence of underperformance of masterpieces, meaning expensive paintings tend to underperform the art market index. A further study reveals that the underperformance could be consistent with overbidding at auctions. The evidence is mixed on whether the "law of one price" holds in the New York auction market.
\end{abstract}

(JEL G14, Z10)

\footnotetext{
${ }^{1}$ Department of Finance and Department of Operations Management, Stern School of Business, New York University, 44 West 4th Street, New York, NY 10012-1126. We have benefited from helpful discussions with Will Goetzmann, Robert Solow and Larry White on art as an investment. We are grateful to Jennifer Bowe, Jin Hung and Loan Hong for able research assistance. We would also like to thank Mathew Gee of the Stern Computer Department for his tireless efforts in rationalizing our database. We also wish to thank John Ammer, John Campbell, Victor Ginsburgh, Robert Hodrick, Burton Malkiel, Tom Pugel and seminar participants at Temple University and University of Southern California for helpful comments and John Campbell for his latent variable model algorithm. All errors are ours.

(C) Jianping Mei and Michael Moses.
} 


\title{
Art as an Investment and the Underperformance of Masterpieces
}

\begin{abstract}
This paper constructs a new data set of repeated sales of artworks and estimates an annual index of art prices for the period 1875-2000. Contrary to earlier studies, we find art outperforms fixed income securities as an investment, though it significantly under-performs stocks in the US. Art is also found to have lower volatility and lower correlation with other assets, making it more attractive for portfolio diversification than discovered in earlier research. There is strong evidence of underperformance of masterpieces, meaning expensive paintings tend to underperform the art market index. A further study reveals that the underperformance could be consistent with overbidding at auctions. The evidence is mixed on whether the "law of one price" holds in the New York auction market.
\end{abstract}

(JEL G14, Z10) 
Two major obstacles in analyzing the art market are heterogeneity of artworks and infrequency of trading. The present paper overcomes these problems by constructing a new repeated-sales data set based on auction art price records at the New York Public Library as well as the Watson Library at the Metropolitan Museum of Art. As a result, we have a significant increase in the number of repeated sales compared to earlier studies by William J. Baumol (1986) and William N. Goetzmann (1993). ${ }^{2}$ For the artworks included in the present study, we have 4,896 price pairs covering the period $1875-2000$. With a larger data set, we are able to construct an annual art index as well as annual sub-indices for American, Old Master, Impressionist and Modern paintings for various time periods. The annual indices are then used to address the question of whether the risk-return characteristics of paintings compare favorably to those of traditional financial assets, such as stocks and bonds.

The larger data set also permits us to test three propositions frequently advanced by art dealers and economists. The first one states that art investors should buy only the top works of established artists (masterpieces) or buy the most expensive artwork they can afford. The empirical evidence on the return performance of masterpieces is mixed. James E. Pesando (1993) presented strong evidence of underperformance while Goetzmann (1996) found no such evidence. Our study will extend their analysis with a new testing procedure based on repeated sales regression (RSR).

The second one states that art investors at auctions suffer from overbidding behavior, that is the existence of excess payment above intrinsic value which lead to below average future returns. ${ }^{3}$ We will study this proposition by using multiple repeated sales data. One major obstacle for testing the proposition is that the intrinsic value of the property is not observable. This paper partially circumvents this problem by assuming art value is determined by its corresponding market index. As a result, given original purchase price and the market index, we can compute a

\footnotetext{
2 Goetzmann (1993) uses price data recorded by Gerald Reitlinger (1961) and Enrique Mayer (19711987) to construct a decade art index based on paintings which sold two or more times, during the period 1715-1986. His data set contains 3,329 price pairs. Baumol (1986) uses a subset of the data recorded by Reitlinger (1961) to study the returns on paintings during the period 1652-1961. His data set contains 640 price pairs. Buelens and Ginsburgh (1993) re-exams Baumol's work with different sample periods. Pesando (1993) uses data for repeat sales of modern prints which has 27,961 repeat sales. But his data only covers a short time span from 1977 to 1992.

3 Note the difference between overbidding and winner's curse is that winner's curse refers to systematic overpayment of bidders at common value auctions while overbidding in the paper just refers to the fact of overpayment and its negative impact on future returns.
} 
"fair value" for the property and measure excess payment by taking the difference between purchase price and "fair value". If there is a significant negative relationship between excess payment and future returns, then there is evidence on the presence of overbidding. Numerous studies have examined common value auctions in which market participants may be susceptible to excessive bidding. Due to the difficulties of observing the common value and measuring future returns, the empirical literature on common value auctions is long on experimental evidence and relatively short on field data. ${ }^{4}$ Our study will add to the field literature by providing an empirical study of overbidding in art auction markets. We will also try to link the underperformance of masterpieces to overbidding.

The third proposition states that prices realized for identical paintings at different locations at the same time should be the same. Pesando (1993) compared prices of alternate copies of same prints sold at New York Sotheby's and Christie's and he found substantial evidence of violation of the "law of one price" during the 1977-1992 period. While no art piece in our data has ever been sold simultaneously in both auction houses, we will conduct a test of the "law of one price" by examining return differentials for artworks sold at different auction houses over much longer time periods. If there is systematic pricing bias from one auction house to the other, then we should expect to see systematic difference in returns for artworks sold at different houses. We will examine the return differentials with a RSR procedure that is different from Pesando (1993).

The remainder of the paper is organized as follows. Section I describes the art auction data set and provides a discussion of sampling biases. Section II reviews the repeated sales regression procedure used to estimate the index for painting prices and provides an asset-pricing framework for estimating the systematic risk of paintings. Section III provides risk and return characteristics of the estimated art price index. Section IV presents evidence on the underperformance of masterpieces. Section V provides several explanations for the underperformance of masterpieces, including the effects of overbidding in the art auction market. Section VI tests the hypothesis of the "law of one price" while Section VII concludes the paper.

\footnotetext{
4 For experimental evidence, see Samuelson and Bazerman (1985), Weiner, Bazerman and Carroll (1987), and Kagel and Levin (1986). For field evidence on overbidding and winner's curse, see Dessauer (1981) on book publishing, Cassing and Douglas (1980) on baseball free agent, Capen, Clapp and Campbell (1971) and Mead, Moseidjord and Sorensen (1983) on oil drilling rights, and Thiel (1988) on
} 


\section{Painting Data and Biases}

Since individual works of art have yet to be securitized nor are there publicly traded art funds, studying the increase in value of works of art from financial sources is not possible. Gallery or direct-from-artists prices tend not to be reliable or easily obtainable. Repeat sale auction prices however are reliable and publicly available (in catalogues) and can be used as the basis for a data base for determining the change in value of art objects over various holding periods and collecting categories.

We created such a database for the American market, principally New York. For the second half of the $20^{\text {th }}$ Century we searched the catalogues for all American, $19^{\text {th }}$ Century and Old Master, Impressionist and Modern paintings sold at the main sales rooms of Sotheby's and Christie's (and their predecessor firms) from 1950 to 2000.5 If a painting had listed in its provenance a prior public sale, at any auction house anywhere, we went back to that auction catalogue and recorded the sale price. The New York Public Library as well as the Watson Library at the Metropolitan Museum of Art were our major sources for this auction price history. Some paintings had multiple resales over many years resulting in up to 6 resales for some works of art. Each resale pair was considered a unique point in our database that now totals over five thousand entries. Some of the original purchase dates went back to the $17^{\text {th }}$ century. If the art piece was sold overseas, we converted the sale price into US dollars using the long-term exchange rate data provided by Global Financial Data. Our data has continuous observations since 1871 and has numerous observations that allow us to develop an annual art index since 1875 .

As well as analyzing our data as a totality we have also separated it into three popular collecting categories. The first is American Paintings (American) principally created between 1700 and 1950. The second is Impressionist and Modern Paintings (Impressionists) principally created between the third quarters of the $19^{\text {th }}$ and $20^{\text {th }}$ century. The third is Old Master and $19^{\text {th }}$ century paintings (Old Masters) principally created after the $12^{\text {th }}$ century and before the third

bidding behavior in highway construction industry. Also see McAfee and McMillan (1987) for a comprehensive literature survey.

${ }^{5}$ Our data does not include "bought-in" paintings that did not sell due to the fact that the bid was below reservation price. Our data for the year 2000 only includes sales before July. 
quarter of the $19^{\text {th }}$ century. The number of observations in our resale data by year of purchase and sale from 1875-2000 are depicted in Figure 1. For convenience, we will call the first price from each price pair "purchase price" and the second price "sale price" from the perspective of the collector for the time period between the two transactions corresponding to the price pair. They total 4,896 price pairs, which consists of 899 pairs from American, 1,709 from Impressionist, and 2,288 from Old Masters. We can see that our data is rather spotty for the beginning of our sample but increases rapidly after 1935.6 We can also see that most artworks bought are held for long time periods (on average 28 years) so that not many purchases in the early years are sold right away.

The selection bias in the data set is an important issue that bears on the interpretation of our empirical study. The selection procedures based on multiple sales from major US auction houses tend to truncate both sides of the return distribution. Our sample may suffer from a "backward filled" data bias since our transactions data before 1950 are collected only from those paintings that were sold in Christie's and Sotheby's after 1950.7 Given the reputation of the two auction houses, our data may have a bias toward those paintings that have a high value after 1950. However, this "backward filled" bias is mitigated by two facts: first, our data set does have a large number of paintings with poor returns. This is partly due to the fact that auction houses are obliged to sell all estate holdings whether they have high values or not. Auction houses such as Sotheby's and Christie's also have incentives to sell inexpensive artworks from established artists to attract first time collectors. Thus, we do observe prices of artworks that had fallen substantially. Second, our data before 1950 also come from well known auction houses around the world, so our data principally include works of artists established at the time of purchase. This will tend to moderate the upward bias of our return estimates due to

\footnotetext{
6 Note that the scarcity of "sales" data before 1935 was compensated to some extent by more "purchase" data in the repeated sales regression, which use both sets of data in the construction of the art market index. However, the scarcity of data before 1935 would impact the volatility of the index since the art index portfolio then was poorly diversified because of few artworks in the portfolio.

7 This bias is similar to the "back-filled" data bias for emerging market stocks where historical data on their returns is "back-filled" conditional upon the survival of emerging markets. Thus, data for those emerging markets that submerged as result of revolution or economic turmoil were not included, which tend to create a downward bias. See Harvey (1995) for a detailed discussion. We like to note, however, unlike Russian bonds and Cuban stocks, paintings from established artists sold in auctions seldom disappear from the market completely. Thus, one can still observe a large number of art pieces sold at estate auctions at a fraction of their purchase price.
} 
survival. Moreover, expensive paintings today that were bought a long time ago at low prices directly from dealers or artists are not included in our sample due to a lack of transaction records. This will partially offset the upward bias as well. Moreover, masterpieces collected by museums through donation rather than auction sales are also excluded from the sample, further offsetting the upward bias.

In addition to these selection biases, Orley Ashenfelter, Kathryn Graddy, and Margaret Stevens (2001) pointed out that not all items that are put up for sale at auctions are sold because some final bids may not reach the reservation prices. Goetzmann (1993) also argues that the decision by an owner to sell a work of art (and consequently the occurrence of a repeat sale in the sample) could be conditional upon whether or not the value has increased. These would also tend to bias the estimated return upward. ${ }^{8}$ Because of these biases, the mean annual return to art investment provided by repeated-sale data should be regarded as approximate, or as an upper bound on the average return obtained by investors over the period. The return could be further reduced by transaction costs. We like to note, however, that return estimates for financial assets, to some extent, also could suffer from the same biases, such as lack of market liquidity, transaction costs and survival.

\section{Methodology for Estimating the Art Index and Asset Pricing}

The repeat-sales regression (RSR) uses the purchase and sale price of individual properties to estimate the fluctuations in value of an average or representative asset over a particular time period. Robert C. Anderson (1974), Goetzmann (1993), and Pesando (1993) apply it to the art market. The benefit of using the RSR is that the resulting index is based upon price relatives of the same painting that controls for the differing quality of assets. Thus, it does not suffer from arbitrary specifications of a hedonic model. The drawback is that the index is constructed from multiple sales, which is a subset of the available transactions. Olivier Chanel,

\footnotetext{
${ }^{8}$ Goetzmann $(1993,1996)$ also argues that auction transactions may not adequately reflect an important element of risk for the art investor: stylistic risk. In other words, the future sales price will depend upon the number of people who wish to buy the work of art when it is put up for sale. Since the repeat-sales data principally reflect auction transactions, they necessarily focus upon artworks that have a broad demand to attract a large number of competitive bidders. Thus, the repeat-sales records will fail to capture the price fluctuations of paintings that are not broadly in demand. The stylistic risk is similar in
} 
Louis-Andre Gerard-Varet, and Victor Ginsburgh (1996) provided a detailed discussion on the weakness of RSR model.

We begin by assuming that the continuously compounded return for a certain asset $\mathrm{i}$ in period $t, r_{i, t}$, may be represented by $\mu_{t}$, the continuously compounded return of a price index of art, and an error term:

$$
r_{i, t}=\mu_{t}+\eta_{i t}
$$

where $\mu_{\mathrm{t}}$, may be thought of as the average return in period t of paintings in the portfolio. We will use sales data about individual paintings to estimate the index $\mu$ over some interval $t=1 \ldots$ T. Here, $\mu$ is a T-dimensional vector whose individual elements are $\mu_{t}$. The observed data consist of purchase and sales price pairs, $\mathrm{P}_{\mathrm{i}, \mathrm{b}}$, and $\mathrm{P}_{\mathrm{i}, \mathrm{s}}$, of the individual paintings comprising the index, as well as the dates of purchase and sale, which we will designate with $\mathrm{b}_{\mathrm{i}}$, and $\mathrm{s}_{\mathrm{i}}$. Thus, the logged price relative for asset $i$, held between its purchase date $b_{i}$ and its sales date, $s_{i}$, may be expressed as

$$
\begin{aligned}
r_{i} & =\ln \left(\frac{P_{i, s}}{P_{i, b}}\right)=\sum_{t=b_{i}+1}^{s_{i}} r_{i, t} \\
& =\sum_{t=b_{i}+1}^{s_{i}} \mu_{t}+\sum_{t=b_{i}+1}^{s_{i}} \eta_{i, t}
\end{aligned}
$$

Let $\mathbf{r}$ represent the $\mathrm{N}$-dimensional vector of logged price relatives for $\mathrm{N}$ repeated sales observations. Goetzmann (1992) shows that a generalized least-squares regression of the form

$$
\hat{\mu}=\left(\mathrm{X}^{\prime} \Omega^{-1} \mathrm{X}\right)^{-1} \mathrm{X}^{\prime} \Omega^{-1} r
$$

provides the maximum-likelihood estimate of $\mu$, where $\mathrm{X}$ is an NxT matrix, which has a row of dummy variables for each asset in the sample and a column for each holding interval. $\Omega$ is a weighting matrix, whose weights could be set as the times between sales as in Goetzmann

many respects to the liquidity risk in financial markets, where prices of assets are affected not only by fundamental values but also by market liquidity. 
(1993) or could be based on error estimates from a three-stage-stage estimation procedure used by Karl E. Case and Robert J. Shiller (1987). ${ }^{9}$

To calculate the standard errors associated with estimation error for any statistic, such as the mean return of the art index, we first let $\mu$ and $V$ represent the whole set of return parameters and their variance-covariance matrix respectively. Next, we write any statistic, such as the mean return, as a function $\mathrm{f}(\mu)$ of the parameter vector $\mu$. The standard error for the statistic is then estimated as the square root of $\mathrm{f}_{\mu}{ }^{\prime} \mathrm{Vf} \mathrm{f}_{\mu}$, where $\mathrm{f}_{\mu}$ is the gradient of the statistic with respect to the parameters $\mu$. This is often called the $\delta$ method in econometrics.

To estimate the systematic risk of art as investment, we follow John Y. Campbell (1987) by assuming that capital markets are perfectly competitive and frictionless, with investors believing that asset returns are generated by the following K-factor model:

$$
e_{i, t+1}=E_{t}\left[e_{i, t+1}\right]+\sum_{k=1}^{K} \beta_{i k} f_{k, t+1}+\xi_{i, t+1}
$$

Here $e_{i, t+1}$ is the excess return on asset $i$ held from time $t$ to time $t+1$, and represents the difference between return on asset $i$ and the US treasury bill rate. $E_{t}\left[e_{i, t+1}\right]$ is the expected excess return on asset $i$, conditional on information known to market participants at the end of time period $\mathrm{t}$. We assume that $\mathrm{E}_{\mathrm{t}}\left[\mathrm{f}_{\mathrm{k}, \mathrm{t}+1}\right]=0$ and that $\mathrm{E}_{\mathrm{t}}\left[\xi_{\mathrm{i}, \mathrm{t}+1}\right]=0$. The conditional expected excess return is allowed to vary through time in the current model but the beta coefficients are assumed to be constant. This ability of $\mathrm{E}_{\mathrm{t}}\left[\mathrm{e}_{\mathrm{i}, \mathrm{t}+1}\right]$ to vary through time is absent in prior art studies. Equilibrium asset pricing suggests the following linear pricing relationship:

\footnotetext{
${ }^{9}$ The RSR is known to introduce certain biases in the estimated series. The most serious of these are a spurious negative autocorrelation in the estimated return series. This bias is potentially severe when the number of assets in the sample is low, and it is strongest at the beginning of the estimated series, when the sample is small. Goetzmann (1992) propose a two-stage Bayesian regression to mitigate the negative autocorrelation of the series over the early periods. The Bayesian formulation imposes an additional restriction that the return series $\mu$, is distributed normally and is independently and identicallydistributed. The effect on the estimate is dramatic for the early period when data are scarce, and minimal for the period when data are plentiful. The form of the- Bayesian estimator is:

$$
\mu_{\text {Bayes }}=\left[\left(\mathrm{X}^{\prime} \Omega^{-1} \mathrm{X}\right)+\kappa\left(I-\frac{1}{T} J\right)\right]^{-1} \mathrm{X}^{\prime} \Omega^{-1} r
$$

Goetzmann and Peng (2001) also proposed an alternative repeated sales estimate that is unbiased and based on arithmetic average of returns.
} 


$$
E_{t}\left[e_{i, t+1}\right]=\sum_{k=1}^{K} \beta_{i k} \lambda_{k t}
$$

where $\lambda_{\mathrm{kt}}$ is the "market price of risk" for the k'th factor at time t. ${ }^{10}$

Now suppose that the information set at time $t$ consists of a vector of $L$ forecasting variables $X_{n t}, n=1 \ldots L$ (where $X_{1 t}$ is a constant), and that conditional expectations are a linear function of these variables. Then we can write $\lambda_{\mathrm{kt}}$ as

$$
\lambda_{k t,}=\sum_{n=1}^{L} \theta_{k n} \mathrm{X}_{n t}
$$

and plug it into equation (5) and collect terms, it becomes,

$$
E_{t}\left[e_{i, t+1}\right]=\sum_{k=1}^{K} \beta_{i k} \sum_{n=1}^{L} \theta_{k n} \mathrm{X}_{n t}=\sum_{n=1}^{L} \alpha_{i n} \mathrm{X}_{n t}
$$

Equations (5) and (7) combined are sometimes called a multi-factor "latent-variable" model. ${ }^{11}$ The model implies that expected excess returns are time-varying and can be predicted by the forecasting variables in the information set. From equation (7), we can see that the model puts some restrictions on the coefficients of $\alpha_{\mathrm{ij}}$ :

$$
\alpha_{i j}=\sum_{k=1}^{K} \beta_{i k} \theta_{k j}
$$

Here, $\beta_{\mathrm{ik}}$ and $\theta_{\mathrm{kj}}$ are free parameters. We will use the regression system in equation (7) to see to what extent the forecasting variables, $X$, predict excess returns in art investment and to see how closely the risk premium on art move with those on other assets. In general, we do not wish to assume that we have included all of the relevant variables that carry information about factor

${ }^{10}$ Equation (2) states that the conditional expected rate of return should be a linear function of factor risk premiums, with the coefficients equal to the betas of each asset. This type of linear pricing relationship can be generated by a number of inter-temporal asset pricing models, under either a no arbitrage condition or through a general equilibrium framework. See for example, Ross (1976).

${ }^{11}$ For more details on this model, see Campbell (1987) and Ferson and Harvey (1990). 
premiums. Fortunately, the methods described above are robust to omitted information. ${ }^{12}$ The regression system of equation (7) given the restriction in equation (8) can be estimated and tested using Lars P. Hansen's (1982) Generalized Method of Moments (GMM). Our methodology here has several distinctive advantages over previous studies. First, it allows for time-varying risk premiums. Second, the GMM estimation procedure adjusts for heteroskedasticity in the error terms and permits contemporaneous correlation among the error terms across assets. A more detailed discussion of this estimation procedure is provided in the Appendix.

In computing $e_{i, t+1}$, we use return indices from six different asset class: the Art index, Standard and Poor's 500 Total Return Index, the Dow Jones Industrial Total Return Index, the US Government Bonds Total Return Index, the US Corporate Bond Total Return Index, and the United States Treasury Bills Total Return Index. ${ }^{13}$ With the exception of the art index, the sources of these data are from Federal Reserve Board and Global Financial Data (5th edition), which has derived its data from historical data on prices and yields collected by Standard and Poor's, the Cowles Commission and G. William Schwert (1988).

\section{Risk and Return Characteristics of the Art Price Index}

Figure 2 provides a graphic plot of the art index over the 1875-2000 period with the base year index set to be 1 . The index is estimated with 4,896 pairs of repeated sale prices. Our reported art index is based on the three-stage-least-square procedure proposed by Case and Shiller (1987). ${ }^{14}$ The Adjusted R-squares for the estimation is 0.64 , suggesting the art index

12 By taking conditional expectations of equation (2), it is straightforward to show that the pricing restrictions hold in the same form when a subset of the relevant information is used. A more detailed elaboration of this robustness issue is discussed in Campbell (1987).

13 To estimate equation (7), we also use the following forecasting variables $\mathrm{X}_{\mathrm{nt}}$ which are known to the market at time $t$. They include a constant term, the yield on US treasury bills, the dividend yield on Standard and Poor's 500 index, the dividend payout ratio on the Standard and Poor's 500 index, the spread between the yields on Moody's Baa Corporate Bond and US government bonds, and the spread between the yields on US government bonds and US treasury bills. The dividend yield and dividend payout variables capture information on expectations about future cash flows and required returns in the stock market. The two bond spread variables tells us the default premium and the slope of the term structure of interest rates. These variables have been used by Campbell (1987), Fama and French (1988, 1989), Ferson and Harvey (1991), and Lamont (1998), among others.

14 We use the Case and Shiller (1987) procedure because it allows us to adjust for a downward bias in annual returns estimation due the log price transformation (see Goetzmann (1992)). We have also 
explains $64 \%$ of the variance of sample return variation. The F-statistic equals 104.32 with a significance level equal to 0.000 , indicating the index is a highly significant common return component of our art portfolios. Due to a smaller number of observations, the three sub-indices, American, Impressionist, and Old Masters, were estimated only for the 1941-2000, 1941-2000, and 1900-2000 periods respectively. The figure shows a sharp rise in prices in the 1980s with the art index peaked at 8640 in 1990 followed by a 36\% drop in 1991 . We can also see that, even after ten years of market adjustment, the impressionist paintings still have not recovered from its high level of 1990. Thus, performance is much affected by the bear market in art of last ten years. While the boom and bust was well documented in the art market, the price indices allow us to estimate the precise time and magnitude of the price change. Our indices have also identified major price drops during the 1974-75 oil crisis and 1929-1934 depression.

Table 1 provides summary statistics on the behavior of real returns for each of our six asset classes. The real returns are computed as nominal return minus the annual inflation using the US CPI index. For each variable, we report the mean, standard deviation, and its correlation with other assets. We also report the standard deviation of art return estimates due to estimation error using the $\delta$ method. We can see that our estimates are fairly accurate. The standard error for the mean return estimate was only $0.2 \%$ for the $1950-1999$ period and $0.3 \%$ for the $1875-1999$ period. ${ }^{15}$ Table 1 reveals that art had a real annual compounded return of $8.2 \%$ comparable to that of stocks during the 1950-1999 period. Moreover, art out-performed bonds and treasury bills. Corporate and government bonds derived a 2.2\% and 1.9\% annual return respectively while the S\&P 500 and the Dow Industrial gained 8.9\% and 9.1\% respectively. Our results are quite similar for the 1900-1999 period, though the performance gap between art and stocks widen. The art index also out-performed fixed income securities during the 1875-1999 period. ${ }^{16}$ Moreover, we found that the volatility of art market price index dropped to $21.3 \%$ during the

estimated the art index using GLS and the two-stage Baysian estimation proposed by Goetzmann (1992). The correlation between the Case and Shiller (1987) procedure and the other two procedures are 0.970 and 0.917 , suggesting that the results are quite robust. We have also discovered that the two-stage Baysian estimates tend to have smaller estimation errors though they may be biased.

15 We did not include the year 2000, since our data only has sales from the first half of the year.

16 This result is similar to Goetzmann (1993) during the 1850-1986 period. 
1950-1999 period from 42.8\% during the 1875-1999 period, making the art index just a bit more risky than the two stock indices. ${ }^{17}$

To compare our results with those obtained in earlier studies, we also estimated real returns of various assets for the same sample period as in Goetzmann (1993) and Pesando (1993). The results were reported in the bottom panel of Table 1. While Goetzmann's art index significantly out-performed both stocks and bonds during 1900-1986 sample periods, our art index only outperformed bonds. ${ }^{18}$ We conjecture that the differences in art performance could be partly due to a difference in sample selection, since the artists chosen by Reitlinger (1961, 1963 and 1973) could be affected by his taste and other selection biases. This could bias the performance result upward. In comparison to Goetzmann's findings, our art index also has less volatility (and much lower correlation with other asset class). This could be the result of our larger sample, which makes our art index portfolio to be better diversified and less volatile. Our art index performed better than that of Pesando (1993) who used modern prints sold in US and Europe. He found modern prints under-performed both stocks and bonds during 1977-1992 sample period. Using semi-annual returns, he also found print returns could be less volatile than stock and bonds. ${ }^{19}$ Because of lower volatility and correlation with other assets reported in Table 1, our study suggests that a diversified portfolio of artworks may play a somewhat more important role in portfolio diversification.

In Table 2, we report the estimates of the restricted version of our asset pricing model (4) with restriction (8) imposed. The estimation method used is the GMM procedure of Hansen, using the forecasting variables given in footnote 13. We estimate our model under the assumption that there is only one "priced" systematic factor in the economy $(\mathrm{K}=1)$. With beta normalized to be one for the S\&P 500 index, we observe that the art beta was 0.718 during the sample period and it was significant with a t-statistic of 3.119. The smaller beta on art comparing to the S\&P 500 indicates that art has less systematic risk than the S\&P 500 thus it should be

17 There was a large drop in the volatility of the art index for the most recent sample period. This should be expected, since the number of artworks in our art index portfolio increased rapidly after 1935.

18 It is worth noting that, while both Goetzmann's (1993) and our data include artworks sold internationally, Goetzmann's data are concentrated in UK sales before 1960 and ours are skewed towards auction sales in the US. While our result on art return characteristics is similar to Goetzmann (1996), he did not use a RSR estimation approach in his 1996 paper. 
expect to earn less return than the S\&P 500 over the long run. It also suggests that the art index tends to move in the same direction as the S\&P 500, consistent with a wealth effect from the stock market discussed in Goetzmann (1993). In addition, the higher systematic risk on art compared to bonds implies that art should earn a higher return than bonds over the long run. The chi-square test indicates that a one-factor model is rejected by the data but a two-factor model is not rejected. ${ }^{20}$

\section{Do Masterpieces Under-perform?}

A common advice given to their clients by art dealers is to buy the best (i.e. most expensive) artworks they can afford. This presumes that the masterpieces of well known artists will outperform the market. In other words, masterpieces might have a higher expected return than middle-level and lower-level works of art. Contrary to this popular belief, Pesando (1993) discovered that masterpieces actually tend to under perform the market. His discovery was based on repeated sales of modern prints from 1977-1992. Since Pesando's data only cover prints that tend to have much lower value compared to American, Old Masters and Impressionists paintings, one may wonder if this underperformance exists for truly expensive artworks. Moreover, Goetzmann (1996) found no evidence of underperformance of masterpieces. Using repeated sales data covering American, Old Master, Impressionist and Modern paintings, this paper will further examine the performance of masterpieces. We will follow Pesando by using the market price to identify the masterpieces (i.e, expensive paintings are masterpieces). In the first examination, we use prices for all artworks sold between 1875 and 2000. We apply the same repeated sales regression approach used in the section above by adding an additional term in the regression,

19 Pesando's volatility numbers are not directly comparable to ours since his computation was based on semiannual data. Our average return results are also similar to those of Buelens and Ginsburgh (1993) from the 1870-1913 period. Their study was also based on the Reitlinger (1961) data.

20 It is well known in the finance literature that a one-factor CAPM model is often rejected by data. We still report the estimates of the one factor model because the CAPM is quite popular and it is quite interesting to know the beta of the art index. We have also estimated a "two factor" model with a stock market factor and a bond factor. Our results indicate that art still has a positive exposure to the stock market factor. Like other CAPM studies, we have also found some evidence of time-varying betas. The results are available upon request. 


$$
r_{i}=\sum_{t=b_{i}+1}^{s_{i}} \mu_{t}+\gamma\left(s_{i}-b_{i}\right) \cdot \ln \mathrm{P}_{i, b}+\sum_{t=b_{i}+1}^{s_{i}} \varepsilon_{i t}
$$

where $\gamma$ is the elasticity of art returns with respect to log price of the property and $\left(\mathrm{s}_{\mathrm{i}}-\mathrm{b}_{\mathrm{i}}\right)$ is the holding period. Here $\gamma$ gives the expected percentage changes in annual returns as a result of a $1 \%$ change in art purchase prices. For the three subcategories, we also repeat the same estimation procedure. In the second exercise, we use prices deflated by the US CPI index, since the nominal value of art may change due to inflation. The results are reported in Table 3 while Figure 3 provide a simple plot of art returns and purchase prices for Old Masters paintings. Our results are uniform across all categories that masterpieces significantly under-performed their respective art market indices. Our $\gamma$ estimate on the American artworks indicates that a 10\% increase in purchase price is expected to lower future annual returns by $0.1 \%$. Moreover, our results are robust to whether nominal prices or real prices are used in the regressions. Thus, our study seems to suggest that art investors should buy less expensive artworks at auctions.

The underperformance of masterpieces is similar to the "small firm effect" documented by K.C. Chan and Nai-Fu Chen (1988) and many others in their study of the capital asset pricing model. These authors discover that small firms with lower market capitalization tend to achieve excess returns not justified by their risk based on single factor market models. Recent studies by Eugene Fama and Kenneth French (1996), however, suggest that firm size could be a proxy for exposure to systematic risk factors. ${ }^{21}$ While it may be possible to argue that masterpieces are less risky or more liquid, we will show in the following section that the underperformance of masterpieces could also be partly explained by overbidding behavior at art auctions.

\section{V: An Explanation of Masterpiece Underperformance}

The concept of overbidding is borrowed from studies of bidding behavior by oil companies in their purchasing of drilling rights to land parcels. Assuming people purchase art as investment, we can describe an art auction as a common value auction, ${ }^{22}$ where the intrinsic value of property is assumed to be worth the same amount to all bidders. Overbidding occurs

\footnotetext{
${ }^{21}$ Alternatively, one may argue that many people purchase art for their own pleasure and more expensive paintings have larger private consumption values. Thus, the negative returns could indicate a higher private consumption value offset by a lower monetary payoff in an efficient art market.

22 For art and wine auctions, see Ashenfelter (1989).
} 
when collectors bid above the intrinsic value of property, which results in the purchased piece receiving less than the expected return or perform poorly comparing to other artworks for which the purchase prices are closer to their values. The higher the winning price in relation to value, the lower the future returns. In other words, the higher the excess payment over value, the lower the expected returns for the future holding period. Notice that overbidding here refers to the negative relationship between excess payments and future returns and not the simple fact that there are excess payments at art auctions.

This paper constructs a new test of overbidding by using multiple sales data from art auctions. The multiple repeated sales data allows us to observe three transaction prices in a row, the purchase price by a first buyer, the purchase price paid by a second buyer, and the sale price obtained by the second buyer. One main difficulty of conducting such a test is that the intrinsic value of art is unobservable so it is impossible for researchers to gain an accurate measure of excess payment. We get around this difficulty by assuming that art value is determined by its corresponding market index. In other words, we assume that art value should increase at the same rate as its market index after the first purchase. As a result, we can measure the excess payment from the second buyer by studying the difference between returns on the art piece and the art index over the holding period for the first buyer. If there is a negative relationship between the excess payment and the second holding period returns, then there is evidence of overbidding. Using 494 sets of multiple sales data spanning from 1875 to 2000, we run two regressions:

$$
e r_{i}=\theta_{0}+\theta_{l} e p_{i}+\zeta_{i}
$$

and

$$
e r_{i}=\theta_{0}+\theta_{1} e p_{i}+\theta_{2} \ln \left(P_{i, b}\right)+\zeta_{i}
$$

where $\mathrm{er}_{\mathrm{i}}$ is excess annual return over the market index for the second holding period on property $\mathrm{i}$ after the second buyer paid $\mathrm{P}_{\mathrm{i}, \mathrm{b}}$. e $\mathrm{ep}_{\mathrm{i}}$ is $\log$ excess payment, which is defined as $\log$ $\left(\mathrm{P}_{\mathrm{i}, \mathrm{b}}, \mathrm{P}_{\mathrm{i}, \mathrm{b}}\right) /\left(\mathrm{I}_{\mathrm{i}, \mathrm{b}}, \mathrm{I}_{\mathrm{i}, \mathrm{b}}\right)$, where $\mathrm{P}_{\mathrm{i}, \mathrm{b}} / \mathrm{P}_{\mathrm{i}, \mathrm{b}}$ is the appreciation of the property during the first holding period and $\mathrm{I}_{\mathrm{i}, \mathrm{b}}, \mathrm{I}_{\mathrm{i}, \mathrm{b}}$ is the index appreciation during the corresponding period. The intuition behind the excess payment is that the relative appreciation of the property over that of the corresponding art index during the same period provides a measure of excess payment on the 
property. If excess payment has no negative impact on future returns, we would expect the coefficient $\theta_{l}$ to be zero in equation (10). Hence, we use equation (10) to measure the direct relationship between excess payment and future returns and we use equation (11) to control for the masterpieces, so that we can rule out the possibility that the low future returns are due to underperformance by masterpieces and not excess payment resulted from overbidding. The results are reported in Table 4 and Figure 4.

Our results suggest that, with the only exception of American art, there is a significant negative relationship between excess payments and future excess returns. Our $\theta_{1}$ estimate for the full art sample indicates that a $10 \%$ increase in excess payment is expected to lower future annual excess returns by $0.15 \%$ from its mean. While the market index might be subject to estimation error, there is clear evidence that future excess returns are negatively related to excess payments, though not all excessive payments resulted in negative future returns. ${ }^{23}$ This negative relationship between excess payments and future excess returns indicate that there is little persistence in art returns. Past winners (which fetched high sale prices at auctions and became masterpieces) tend to under perform the art market index in the future. In other words, there is regression to the mean in the art market.

Due to the fact that the true value of art is not observable, we cannot make a statement whether there is systematic overbidding in the auction market. What our results do show, however, is the presence of overbidding at the cross-sectional level (individual art piece) that are negatively related to future investment returns. In many respects, our results are similar to those found in Werner F. M. De Bondt and Richard Thaler (1989) about the stock market. They discovered a mean reversion in stock returns. Those stocks that outperformed the stock market (winners) in the past tend to under perform in the future while those that under performed (losers) tend to outperform in the future. De Bondt and Thaler attributed this mean reversion to investor over-reaction. Our results confirm that similar mean reversion is present in the art market as well.

23 We have also estimated equation (11) by eliminating the outliers with future excess returns greater than $50 \%$ or lower than $-50 \%$. Our results remain unchanged. We also confirmed our results with data from Impressionists and Old Masters, which had 99 and 288 observations, respectively. The tests for American paintings were not conclusive due to a lack of observations. These results are available upon request. 
Table 4 further shows that the excess payment term remains significant even if we include the log price variable for masterpieces. Our results indicate that, after controlling for the presence of excess payment, masterpieces did not significantly under perform. ${ }^{24}$ In other words, masterpieces were only "cursed" if their buyers paid excessively high prices above the market. It is worth noting here that equation (11) may suffer from an endogeneity problem $\operatorname{since} \ln \left(P_{i, b}\right)$ is also used in the computation of $e r_{i}$ (see Goetzman and Jorion (1993) for a discussion of similar issues). As a robustness check, we have re-estimated equation (11) using various instruments, such as projected $P_{i, b}$, based on the market index or lagged market index. We find our results remain unchanged except that the coefficient on $\ln \left(P_{i, b}\right)$ become insignificant in all cases.

What is also interesting is that even after a century of data from 1875-1975, which showed a significant negative relationship between excess payment and future excess returns, art buyers after 1975 still demonstrated a tendency for overbidding, which resulted in lower average returns. These results are reported in the two bottom panels of Table 4 . We have also broken the sample using other years, such as 1950 and 1960 rather than 1975, and the results remain unchanged. Thus, the puzzle is why the mean reversion is so persistent? One rational explanation is that the mean reversion found in the paper does not allow a dealer to trade profitably by buying low and selling high. To do so, she would have to inventory such paintings, which she would have to put up substantial capital. In addition, she faces approximately $10 \%$ buyer's commission and 6\% seller's commission for dealers (10\% for others). Given the price volatility, the arbitrage is hardly risk-free. Moreover, the data and technology for estimating the art market index may not be available to the average dealer so that she may not be able to estimate excess payment and be aware of the mean reversion in the art auctions.

Another explanation for the mean reversion is that art prices are also determined by private consumption values of artworks. The lack of a well-developed rental market suggests that the owner's personal enjoyment is an important component of the unobserved yield. One could argue that the purpose of the auction is to allocate the item to the person who likes it best. Thus if there is a buyer (or perhaps two, to bid up the price) who is particularly fond of a particular item, then the value should go up when she first sees it. The dividend stream (enjoyment) is higher as long as this buyer lives (or can afford to own it), but will likely be lower again if her

\footnotetext{
${ }^{24}$ As a robustness check, we also estimated equation (12) using excess payment, $\left(\mathrm{P}_{\mathrm{i}, \mathrm{b}}, \mathrm{P}_{\mathrm{i}, \mathrm{b}}\right)-\left(\mathrm{I}_{\mathrm{i}, \mathrm{b}}, \mathrm{I}_{\mathrm{i}, \mathrm{b}}\right)$, and annualized $\log$ excess payment as $\left[\log \left(\mathrm{P}_{\mathrm{i}, \mathrm{b}} / \mathrm{P}_{\mathrm{i}, \mathrm{b}}\right) /\left(\mathrm{I}_{\mathrm{i}, \mathrm{b}} / \mathrm{I}_{\mathrm{i}, \mathrm{b}}\right)\right] /(\mathrm{b} '-\mathrm{b})$. Our results remain unchanged. The
} 
heir (or she) decides to sell it. This ought to produce the mean reversion in relative price changes..$^{25}$ One could easily explain away the under performance of masterpieces by arguing that the lower performance is compensated by a large unobserved aesthetic consumption yield produced by the masterpieces. Difference in risks and liquidity may contribute to a lower expected return for masterpieces as well.

It is possible that a sample selection problem may also contribute to the under performance of masterpieces. When the value of a masterpiece decreases, it is more likely to continue to be sold at a major auction house. Whereas, for less valuable artworks, if their value decreases sufficiently, it may be sold at a lesser auction house or elsewhere and drop out of our sample. Hence the sample-selection problem is greater for other paintings than for masterpieces, and those items that remain in the sample are generating a higher return than the overall art market. ${ }^{26}$ While our data does include many paintings that have dropped substantially in value, further studies are needed for examining the survivorship bias.

\section{VI: Tests of "Law of One Price"}

Pesando (1993) compared prices of identical prints sold in different markets, and he found substantial evidence of violation of "law of one price" during the 1977-1992 period. He found that prices for prints sold at Sotheby's consistently exceed prices of those sold at Christie's. This is puzzling, since one would expect, in the absence of transaction costs, the "law of one price" would dictate that no significant price difference should exist for identical prints of the same artist. Ashenfelter (1989) also discussed the violation of "law of one price" on wine auctions around the world.

This paper provides an alternative test of the "law of one price" using the repeated sales data for original paintings from Christie's and Sotheby's. Our null hypothesis is that there is no difference between prices realized at different auction houses so that the returns realized from different auction houses are equal. To test the above hypothesis, we include a set of annualized return dummies for different locations of transactions in the following repeated sales regression:

results are available upon request.

${ }^{25} \mathrm{We}$ are grateful to John Ammer for providing this alternative explanation.

$26 \mathrm{We}$ are grateful to an anonymous referee for providing this explanation. 


$$
r_{i}=\sum_{t=b_{i}+1}^{s_{i}} \mu_{t}+\sum_{j=1}^{5} \rho_{j}\left(s_{i}-b_{i}\right) \cdot D_{i, j}+\sum_{t=b_{i}+1}^{s_{i}} \varepsilon_{i t}
$$

where $D_{i, j}$ is a set of dummy variables for different locations of transactions defined in Table 5.27 Here, $\rho_{j}$ measures the excess annual return achieved at other auction locations over returns obtained by buying at Christie's and selling at Christie's. Thus, returns obtained by buying at Christie's and selling at Christie's serve as a benchmark. Equation (12) is estimated the same way as equation (9) by adding a few dummy variable columns to the matrix $\mathrm{X}$ in equation (3). The results are presented in Table 5. Comparing to what was found in Pesando (1993), here we have mixed evidence on the "law of one price". The place of transaction did not seem to matter for American paintings. ${ }^{28}$ For impressionist paintings, while the location dummies were not significant for most cases, collectors did receive a statistically significant higher return when their artworks were bought at other auction houses and later sold at Sotheby's. For Old Masters, while the first three location dummies were not significant, our result has shown a significant negative return impact when the paintings were bought at Sotheby's, indicating on average paintings sold at Sotheby's fetch a higher price. In addition, when a old master piece were bough at Sotheby's but were sold at Christie's, it tended to receive a even lower return than selling the piece at Sotheby's instead. However, we like to note that the return differences between the two major auction houses appear to be small. Conditional on art pieces being bought at Christie's, place of sale made no statistical difference for collectors. It only mattered when the art piece was bought at Sotheby's. Our study including all collecting categories over the 1875-2000 period confirmed this result. In addition, the study shows collectors tended to do better when they buy at other auctions but manage to sell their collection at the two major auction houses. This is certainly consistent with the blue chip reputation of the two houses.

\footnotetext{
${ }^{27}$ Due to the construction of our data set of price pairs, there are three possibilities for location of purchase: Christie's, Sotheby's, and other auction houses (Others), while there are only two possibilities for location of sale: Christie's and Sotheby's. Thus, we constructed five dummy variables for six different purchase-sale location combinations. We deleted a few observations because information on purchase locations were not available.

28 Few American paintings were sold at other auctions in our sample so we did not include the first two dummies in our regression analysis.
} 


\section{Conclusions}

This paper constructs a new data set of repeated sales of art paintings and estimates an annual index of art prices for the period 1875-2000. Our data set has more repeated sales data than previous studies and is also broken down by three popular collecting categories. Based on this new data set, our study made the following discoveries: First, contrary to some earlier studies, we find art has been a more glamorous investment than some fixed income securities, though it significantly under-performs stocks. Our art index also has less volatility and much lower correlation with other assets as found in previous studies. As a result, a diversified portfolio of artworks may play a somewhat more important role in portfolio diversification.

Second, our study finds strong evidence of underperformance of masterpieces as in Pesando (1993), which means expensive paintings tend to under perform the art market index. By measuring excess returns based on multiple sales, we have found that the underperformance

of masterpieces could be partly explained by overbidding behavior. We show that those bidders who pay excessive amount relative to "fair market value" tend to obtain lower future returns. This appears to be more pronounced for impressionist paintings that went through a boom and bust cycle in the last twenty years.

Thirdly, there is mixed evidence that the "law of one price" is violated in the New York art auction market. In general, there seem to be little price difference between Christie's and Sotheby's for American and Impressionist paintings. However, we do have some evidence that purchase prices were somewhat higher for Old Masters at Sotheby's for our 1900-2000 sample.

Our results on the return-risk characteristics of artworks and the correlations between art and financial assets have implications for long-term investors. Contrary to established industry wisdom, our results on the performance of masterpieces suggest that investors should not be obsessive with masterpieces and they need to guard against overbidding that exceeds overall market appreciation. We like to note, however, our results may only serve as a benchmark for those artworks bought at major auction houses. Our return estimates could also be biased due to sample selection. In addition, art may be appropriate for long-term investment only so that the transaction costs can be spread over many years.

Our research has left many interesting issues. First, is there a systematic bias in bidding prices so that winning bids always exceed value? In this paper, we have not provided any 
evidence on the presence of systematic overbidding. While the true value of art is unobservable, one may wonder if there is an alternative proxy to value, such as dealer's estimates, that may serve as a proxy so that we may measure the presence of market wide bias in art auctions. ${ }^{29}$ Second, while our study has provided some cross-sectional evidence on the negative relationship between excess payment and future returns so that those who made excess payments are "cursed" to lower average returns, one may wonder if similar time series evidence can be found on the market as whole so that times of great exuberance are also more likely to be followed by disappointing performance. To put it differently, it will be interesting to know whether the art market itself may also follow a mean reversion process. We will leave these for future research.

29 This approach is used by Stuart E. Thiel (1988) in his study of bidding behavior in highway construction industry. 


\section{References}

Anderson, Robert C., "Paintings as Investment" Economic Inquiry, March 1974, 12, 13-26.

Ashenfelter, Orley, "How Auctions Work for Wine and Art," Journal of Economic Perspectives, Summer 1989, 3, 23-36.

Ashenfelter, Orley and Genesove, David, "Testing for Price Anomalies in Real-Estate Auctions," American Economic Review, May 1992, 82, 501-5.

Ashenfelter, Orley, Kathryn Graddy, and Margaret Stevens, "A Study of Sale Rates and Prices in Impressionist and Contemporary Art Auctions", 2001, Working paper.

Baumol, William, "Unnatural Value: or Art Investment as a Floating Crap Game," American Economic Review, May 1986 (Papers and Proceedings), 76, 10-14.

Bryan, Michael F., "Beauty and the Bulls: The Investment Characteristics of Paintings," Economic Review of the Federal Reserve Bank of Cleveland, First Quarter 1985, pp. 2-10.

Buelens, Nathalie and Ginsburgh, Victor, "Revisiting Baumol's 'art as floating crap game", European Economic Review, 1993, pp 1351-1371.

Campbell, John Y., 1987, Stock Returns and the Term Structure, Journal of Financial Economics, 18, 373-399.

Capen, E. C., R. V. Clapp, and W. M. Campbell, "Competitive Bidding in High-Risk Situations," Journal of Petroleum Technology, June 1971, 23, 641-653.

Case, Karl E. and Shiller, Robert J., "Prices of Single-Family Homes Since 1970: New Indexes for Four Cities," New England Economic Review, September - October 1987, 45-56.

Cason, Timothy N., 1995, An Experimental Investigation of the Seller Incentives in the EPA's Emission Trading Auction, The American Economic Review, Vol. 85, 905-922.

Cassings, James, and Richard W. Douglas, Ímplications of the Auction Mechanism in Baseball's Free Agent Draft," Southern Economic Journal, July 1980, 47, 110-21.

Chan, K. C., Nai-Fu Chen, An Unconditional Asset-Pricing Test and the Role of Firm Size as an Instrumental Variable for Risk, Journal of Finance, Vol. 43, No. 2. (Jun., 1988), pp. 309-325.

Chanel, Olivier, Gerard-Varet, Louis-Andre, and Ginsburgh, Victor, The Relevance of Hedonic Price Indices, Journal of Cultural Economics 20, 1996, pp 1-24.

Dessauer, John P., Book Publishing, New York: Bowker, 1981. 
De Bondt, Werner F. M. and Richard Thaler, Does the Stock Market Overreact? Journal of Finance, Vol. 40, December 28-30, 1984. (Jul., 1985), pp. 793-805.

Fama, Eugene and Kenneth French, 1988, Dividend Yields and Expected Stock Returns, Journal of Financial Economics, 22, 3-25.

Fama, Eugene and Kenneth French, 1989, Business Conditions and Expected Return on Stocks and Bonds, Journal of Financial Economics 25, 23-49.

Fama, Eugene F., Kenneth R. French, Size and Book-to-Market Factors in Earnings and Returns, Journal of Finance, Vol. 50, No. 1. (Mar., 1995), pp. 131-155.

Ferson, Wayne and Campbell Harvey, 1991, The Variation of Economic Risk Premiums, Journal of Political Economy, 99, pp. 385-415.

Flores, Renato G., Ginsburgh, Victor and Jeanfils, Philippe, 1999, "Long- and Short-Term Portfolio Choices of Paintings", Journal of Cultural Economics, pp 193-210.

Frey, Bruno and Pommerehne, Werner W., (1989a) Muses and Markets: Explorations in the Economics of the Arts, London: Blackwell, 1989.

Ginsburgh, Victor and Jeanfils, Philippe, Long-term co-movements in international markets for paintings, European Economic Review 39, 1995, pp 538-548.

Goetzmann, William N., "Accounting for Taste: Art and the Financial Markets over Three Centuries," American Economic Review, December 1993, 83, 1370-6.

Goetzmann, William N., "The Accuracy of Real Estate Indices: Repeat Sale Estimators," Journal of Real Estate Finance and Economics, March 1992, 5, 5-53.

Goetzmann, William N., "How Costly is the Fall From Fashion? Survivorship Bias in the Painting Market," Economics of the Arts - Selected Essays, 1996. pp 71-84.

Goetzman, Will, and Philippe Jorion, 1993, Testing the predicative power of dividend yields, Journal of Finance 48, 663-680.

Goetzmann, William N., and Liang Peng, 2001, "The Bias Of The RSR Estimator And The Accuracy Of Some Alternatives", Yale SOM Working Paper No. ICF - 00-27.

Hansen, Lars Peter, Large Sample Properties of Generalized Method of Moments Estimators, Econometrica, Vol. 50, No. 4. (Jul., 1982), pp. 1029-1054.

Harvey, Campbell R., 1989, Time-Varying Conditional Covariances in Tests of Asset Pricing Models, Journal of Financial Economics 24: 289-317. 
Harvey, Campbell R, 1995, Predictable Risk and Returns in Emerging Markets, Review of Financial Studies, Vol. 8, No. 3., pp. 773-816.

Kagel, John H. and Dan Levin, “The Winner's Curse and Public Information in Common Value Auctions," American Economic Review, December 1986, 76, 894-920.

Lamont, Owen, 1998, Earnings and Expected Returns, Journal of Finance, 1563-1588.

McAfee, R. Preston, and John McMillan, Auctions and Bidding, Journal of Economic

Perspectives - June 1997, Pages 699-737.

Mayer, Enrique, International Auction Records, New York: Mayer \& Archer Fields, various years.

Mead, Walter J., Asbjorn Moseidjord, and Philip E. Sorensen, "The Rate of Return Earned by Lessees under Cash Bonus Bidding of OCSOil and Gas Leases," The Energy Journal, 1983, 4, $37-52$.

Pesando, James E. “Art as an Investment: The Market for Modern Prints" American Economic Review, December 1993, 83, pp. 1075-1089.

Phelps-Brown, E. H. and Hopkins, Sheila, "Seven Centuries of the Price of Consumables, Compared with Builders’ Wage-Rates,” Economica, November 1956, 23 296-314.

Reitlinger, Gerald, The Economics of Taste, Vol. 1, London: Barrie and Rockcliff, 1961; Vol. 2, 1963; Vol. 3, 1971.

Ross, Stephen, 1976, The Arbitrage Theory of Capital Asset Pricing, Journal of Economic Theory, 13, 341-360.

Samuelson, William F, and Max H. Bazerman, "The Winner's Curse in Bilateral Negotiations," Research in Experimental Economics, 1985, 3, 105-137.

Schwert, G. William, "Indexes of United States Stock Prices from 1802 to 1987," National Bureau of Economic Research Working Paper \#2985.

Thaler, Richard H., “Anomalies the Winner's Curse”, Journal of Economic Perspectives Volume 2, Number 1, Winter 1998, Pages 191-202.

Thiel, Stuart E., Some Evidence on the Winner's Curse, The American Economic Review, Vol. 78, No. 5. (Dec., 1988), pp. 884-895.

Weiner, Sheryl, Max Bazerman, and John Carroll, "An Evaluation of Learning in the Bilateral Winner's Curse," unpublished manuscript, Northwestern University, 1987. 


\section{Appendix:}

To test the restriction in equation (4), we first renormalized the model by setting the factor loadings of the first $K$ assets as follows: $\beta_{i j}=1$ (if $j=i$ ) and $\beta_{i j}=0$ (if $j \neq i$ ) for $1 \leq i \leq K$. Next, we partition the excess return matrix $R=\left(R_{1}, R_{2}\right)$, where $R_{1}$ is a TxK matrix of excess returns of the first $\mathrm{K}$ assets and $\mathrm{R}_{2}$ is a $\mathrm{Tx}(\mathrm{N}-\mathrm{K})$ matrix of excess returns on the rest of the assets. Using equations (7), we can derive the following regression system

$$
R_{1}=X \Theta+v_{1} \text { and } R_{2}=X \alpha+v_{2}
$$

where $\mathrm{X}$ is a TxL matrix of the forecasting variables, $\Theta$ is a matrix of $\theta_{\mathrm{ij}}$ and $\alpha$ is a matrix of $\alpha_{\mathrm{ij}}$. If the linear pricing relationship in equation (5) holds, the rank restriction implies that the data should not be able to reject the null hypothesis $H_{0}: \alpha=\Theta B$, where $B$ is a matrix of $\beta_{i j}$ elements.

Following Hansen (1982), we first construct a $\mathrm{N} x \mathrm{~L}$ sample mean matrix: $\mathrm{g}_{\mathrm{T}}=\mathrm{U}^{\prime} \mathrm{X} / \mathrm{T}$ where $\mathrm{E}\left(\mathrm{U}^{\prime} \mathrm{X}\right)=0$ because the error term in system (4) has conditional mean zero given the instruments $\mathrm{X}$ from equation (7). Next, we stack the column vector on top of each other to obtain a NLx1 vector of $g_{\mathrm{T}}$. A two-step algorithm is then used to find an optimal solution for the

quadratic form, $g_{T}{ }^{\prime} W^{-1} g_{T}$, by minimizing over the parameter space of $(\Theta, \alpha)$. In the first step, the identity matrix is used as the weighting matrix W. After obtaining the initial solution of $\Theta_{\mathrm{O}}$ and $\alpha_{0}$, we next calculate the residuals $v_{1}$ and $v_{2}$ from the above system of equations and construct the following weighting matrix: $W=\frac{1}{T} \sum_{t}\left(v_{t} v_{t}\right) \otimes\left(Z_{t} Z_{t}^{\prime}\right)$, where $\otimes$ is the Kronecker product. Next, we use the above weighting matrix to resolve the optimization problem of minimizing $\mathrm{g}_{\mathrm{T}}{ }^{\prime} \mathrm{W}^{-1} \mathrm{~g}_{\mathrm{T}}$ over the choice of $(\Theta, \alpha)$. Hansen proved that under the null hypothesis (i.e. when the model is correctly specified), $\mathrm{Tg}_{\mathrm{T}}{ }^{\prime} \mathrm{W}^{-1} \mathrm{~g}_{\mathrm{T}}$, is asymptotically chi-square distributed, with the degrees of freedom equal to the difference between the number of orthogonality conditions and the number of parameters estimated: $\mathrm{NxL}-[\mathrm{KxL}+(\mathrm{N}-\mathrm{K}) \mathrm{x} \mathrm{K}]=(\mathrm{N}-\mathrm{K})(\mathrm{L}-\mathrm{K})$, where $\mathrm{N}$ is the number of assets studied, $\mathrm{K}$ is the number of factor loadings, and $\mathrm{L}$ is the number of forecasting variables. After obtaining the weighted sum of squared residuals, we perform a chi-square test to determine if the data rejects the restricted regression system (8). 
Table 1-- Summary Statistics of Real Returns

\begin{tabular}{|c|c|c|c|c|c|c|c|}
\hline & & Art & S\&P500 & Dow & Gov Bond & Corp Bond & T-Bill \\
\hline \multirow[t]{2}{*}{ 1950-1999 } & Mean & $\begin{array}{c}0.082 \\
{[0.002]}\end{array}$ & 0.089 & 0.091 & 0.019 & 0.022 & 0.013 \\
\hline & S.D. & $\begin{array}{c}0.213 \\
{[0.016]}\end{array}$ & 0.161 & 0.162 & 0.095 & 0.092 & 0.023 \\
\hline \multirow[t]{2}{*}{ 1900-1999 } & Mean & $\begin{array}{c}0.052 \\
{[0.003]}\end{array}$ & 0.067 & 0.074 & 0.014 & 0.020 & 0.011 \\
\hline & S.D. & $\begin{array}{c}0.355 \\
{[0.048]}\end{array}$ & 0.198 & 0.222 & 0.086 & 0.084 & 0.049 \\
\hline \multirow[t]{2}{*}{ 1875-1999 } & Mean & $\begin{array}{c}0.049 \\
{[0.003]}\end{array}$ & 0.066 & 0.074 & 0.020 & 0.029 & 0.018 \\
\hline & S.D. & $\begin{array}{c}0.428 \\
{[0.047]}\end{array}$ & 0.087 & 0.208 & 0.080 & 0.080 & 0.048 \\
\hline
\end{tabular}

Correlations Among Real Returns (1950-1999)

\begin{tabular}{lcccccc}
\hline Art Index & 1.00 & & & & & \\
S\&P 500 Index & 0.04 & 1.00 & & & & \\
Dow Industrial & 0.03 & 0.99 & 1.00 & & & \\
Government Bonds & -0.15 & 0.33 & 0.28 & 1.00 & & \\
Corporate Bonds & -0.10 & 0.38 & 0.33 & 0.95 & 1.00 & \\
Treasury Bills & -0.03 & 0.27 & 0.25 & 0.61 & 0.63 & 1.00 \\
\hline
\end{tabular}

\section{Comparison with Earlier Studies in Real Returns}

\begin{tabular}{lccccccc}
\hline \multirow{2}{*}{$1900-1986$} & Goetzamnn & Art & S\&P500 & Gov Bond Corp Bond & T-Bill \\
& Mean & 0.133 & 0.052 & 0.057 & 0.008 & 0.015 & 0.009 \\
& S.D. & 0.519 & 0.372 & 0.207 & 0.082 & 0.081 & 0.052 \\
& & & & & & & \\
$1977-1992$ & Mean & 0.015 & 0.078 & 0.088 & 0.051 & 0.056 & 0.024 \\
& S.D. & -- & 0.211 & 0.115 & 0.133 & 0.129 & 0.028 \\
\hline
\end{tabular}

Note: The standard errors associated with estimation error for the statistics are in the brackets. 
Table 2-- Estimation of a one-factor model (4) with pricing restriction imposed.

\begin{tabular}{lll}
\hline $\mathrm{K}=1$ & $\beta_{\mathrm{i} 1}$ & T-Stat
\end{tabular}

Estimated Beta coefficient for the following assets:

Excess return on S\&P 500 Index

$1.000 *$

Excess return on Art Index

0.718

3.119

Excess return on Dow Industrial

$1.160 \quad 25.84$

Excess return on Government Bonds

0.114

3.609

Excess return on Corporate Bonds

0.246

4.845

$\chi^{2}$-statistic of the rank restriction (5): $\quad 28.41$

Significance level:

$\mathrm{P}=0.005$

Notes: Asterisk $\left(^{*}\right)$ indicates the parameter is normalized to be one. The sample period for this table is $1875-1999$, with 125 observations.

Table 3--Tests of the Underperformance of Masterpieces

\begin{tabular}{ccccc}
\hline & American & Impressionist & Old Master & All \\
\hline Sample Period & $1941-2000$ & $1941-2000$ & $1900-2000$ & $1875-2000$ \\
\hline \multicolumn{2}{c}{ Panel A: Test using Nominal Value } & & & \\
$\gamma$ & -0.010 & -0.006 & -0.012 & -0.010 \\
t-stat & -8.071 & -7.792 & -28.32 & -30.54 \\
Panel B: Test using Real Value & & & \\
$\gamma$ & -0.011 & -0.005 & -0.013 & -0.010 \\
t-stat & -8.116 & -7.467 & -27.99 & -30.81 \\
\hline
\end{tabular}

Note: Three-stage-generalized-least square RSR estimation of Case and Shiller (1989) are used to estimate: $r_{i}=\sum_{t=b_{i}+1}^{s_{i}} \mu_{t}+\gamma\left(s_{i}-b_{i}\right) \cdot \ln \mathrm{P}_{i, b}+\sum_{t=b_{i}+1}^{s_{i}} \varepsilon_{i t}$. 
Table 4--Tests of Overbidding

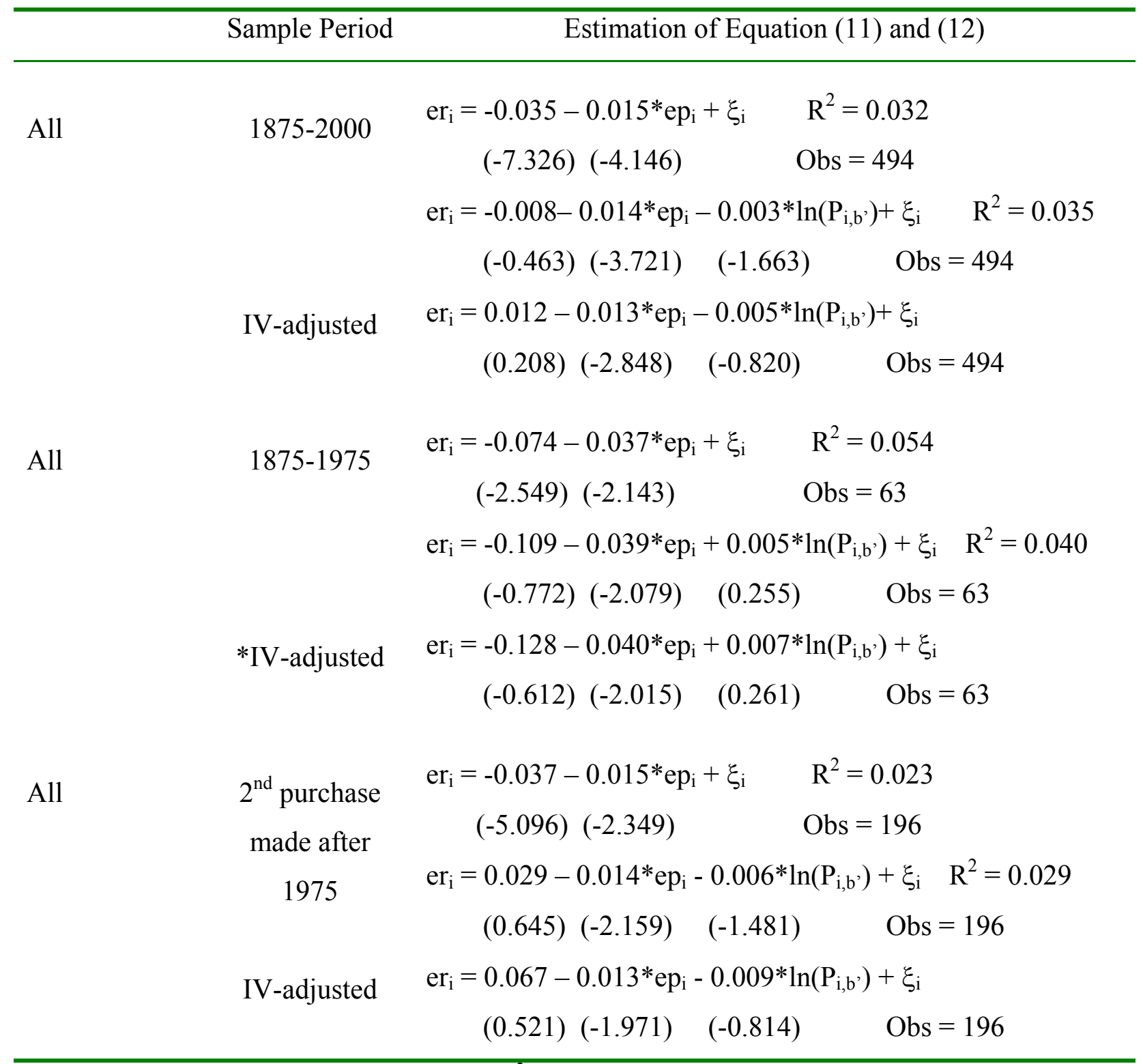

Note: T-statistics are in the parentheses. $\mathrm{R}^{2}$ have been adjusted for degrees of freedom. "IVadjusted" stands for instrumental variable regression using instrument of projected $P_{i, b}$, based on the market index. 
Table 5--Tests of "Law of One Price"

\begin{tabular}{|c|c|c|c|c|c|}
\hline Buy- & Other- & Other- & Christie's- & Sotheby's- & Sotheby's- \\
\hline Sale & Christie's & Sotheby's & Sotheby's & Christie's & Sotheby's \\
\hline & $D_{i, 1}$ & $D_{i, 2}$ & $D_{i, 3}$ & $D_{i, 4}$ & $D_{i, 5}$ \\
\hline American & \multicolumn{5}{|c|}{ 1941-2000 } \\
\hline$\rho$ & - & - & -0.030 & -0.010 & -0.015 \\
\hline t-stat & - & - & -1.640 & -0.870 & -1.477 \\
\hline Impressionist & \multicolumn{5}{|c|}{ 1941-2000 } \\
\hline$\rho$ & -0.001 & 0.049 & 0.002 & -0.002 & -0.006 \\
\hline t-stat & -0.098 & 2.878 & 0.231 & -0.322 & -1.161 \\
\hline Old Master & \multicolumn{5}{|c|}{$1900-2000$} \\
\hline$\rho$ & 0.006 & -0.001 & -0.001 & -0.019 & -0.012 \\
\hline t-stat & 0.924 & -0.187 & -0.293 & -5.461 & -4.218 \\
\hline All & \multicolumn{5}{|c|}{$1875-2000$} \\
\hline$\rho$ & 0.013 & 0.014 & -0.004 & -0.010 & -0.008 \\
\hline t-stat & 3.915 & 4.096 & -1.620 & -3.760 & -3.652 \\
\hline
\end{tabular}

Note: Three-stage-generalized-least square RSR estimation of Case and Shiller (1989) are used to estimate: $r_{i}=\sum_{t=b_{i}+1}^{s_{i}} \mu_{t}+\sum_{j=1}^{5} \rho_{j}\left(s_{i}-b_{i}\right) \cdot D_{i, j}+\sum_{t=b_{i}+1}^{s_{i}} \varepsilon_{i t}$, where $D_{i, j}$ are dummy variables indicate different location of art auctions for each price pair of repeated sales. 
Figure 1: Number of Observations by Purchase and by Sale

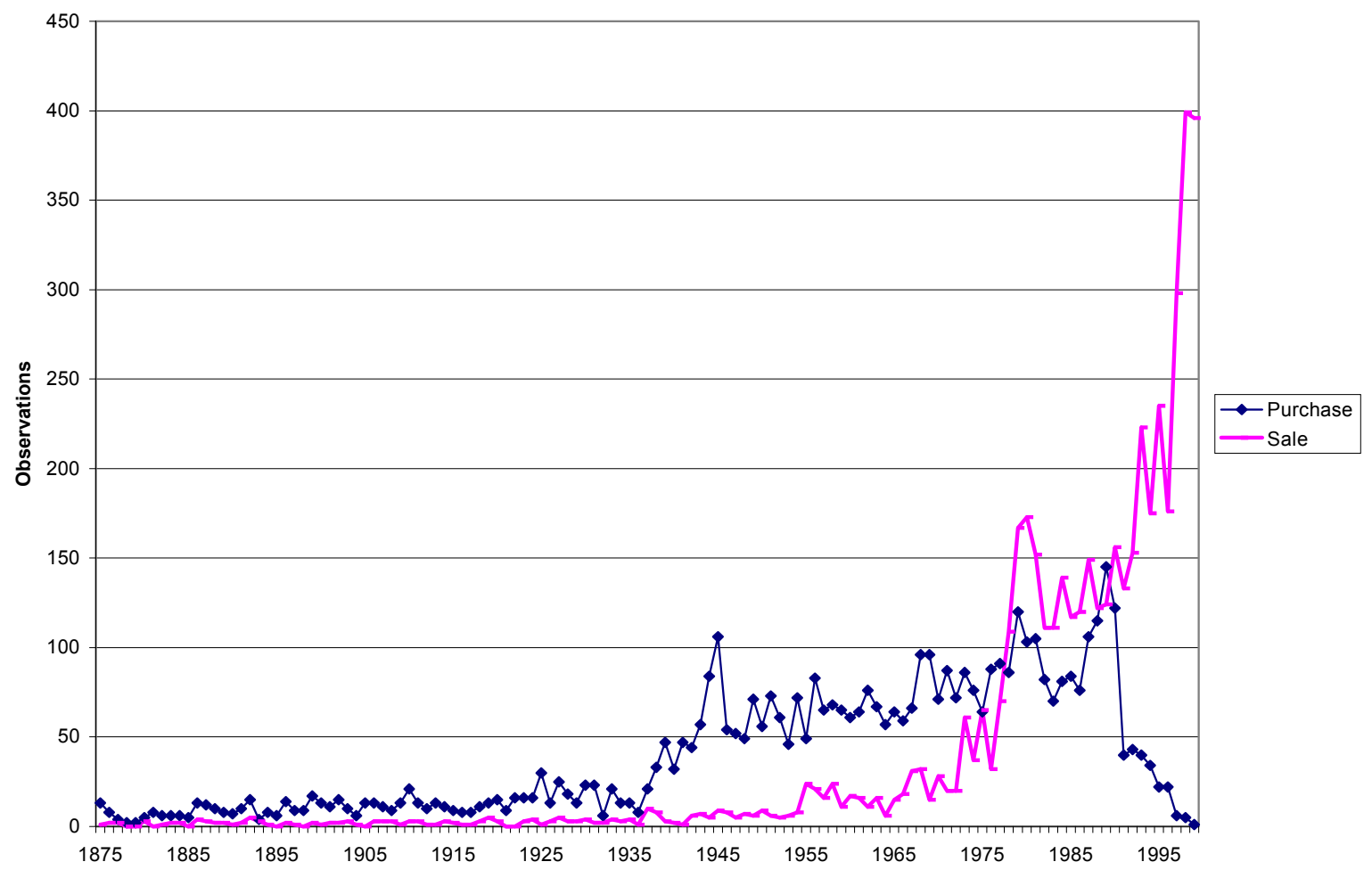

Note: For convenience, we will call the first price from each price pair "purchase price" and the second price "sale price" from the perspective of the collector for the time period between the two transactions of the price pair. 


\section{Figure 2: Nominal Indices}

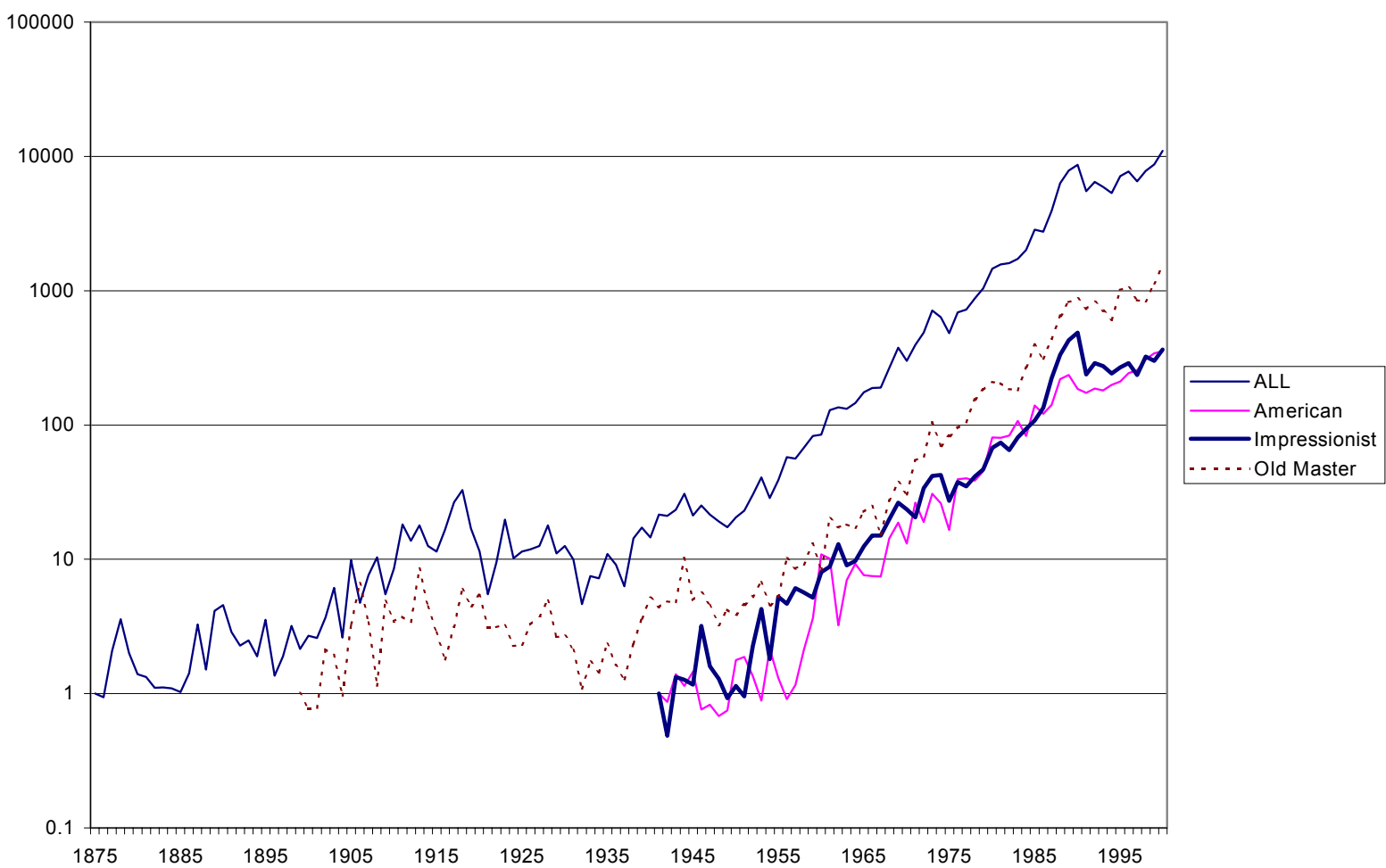

(Base Year: All 1875=1, American 1941=1, Impressionist 1941=1, Old Master 1900=1)

Notes: For the All Art Index, regression statistics for the three-stage-generalized-least square RSR estimation of Case and Shiller: $\mathrm{R}^{2}=0.64, \mathrm{~F}(125,4771)=104.32$ with a significance level equal to 0.000 . Annual returns are computed as $\exp \left(\mu_{\mathrm{t}}+\sigma^{2} / 2\right)-1, \sigma^{2}$ is estimated in the second stage of RSR. 


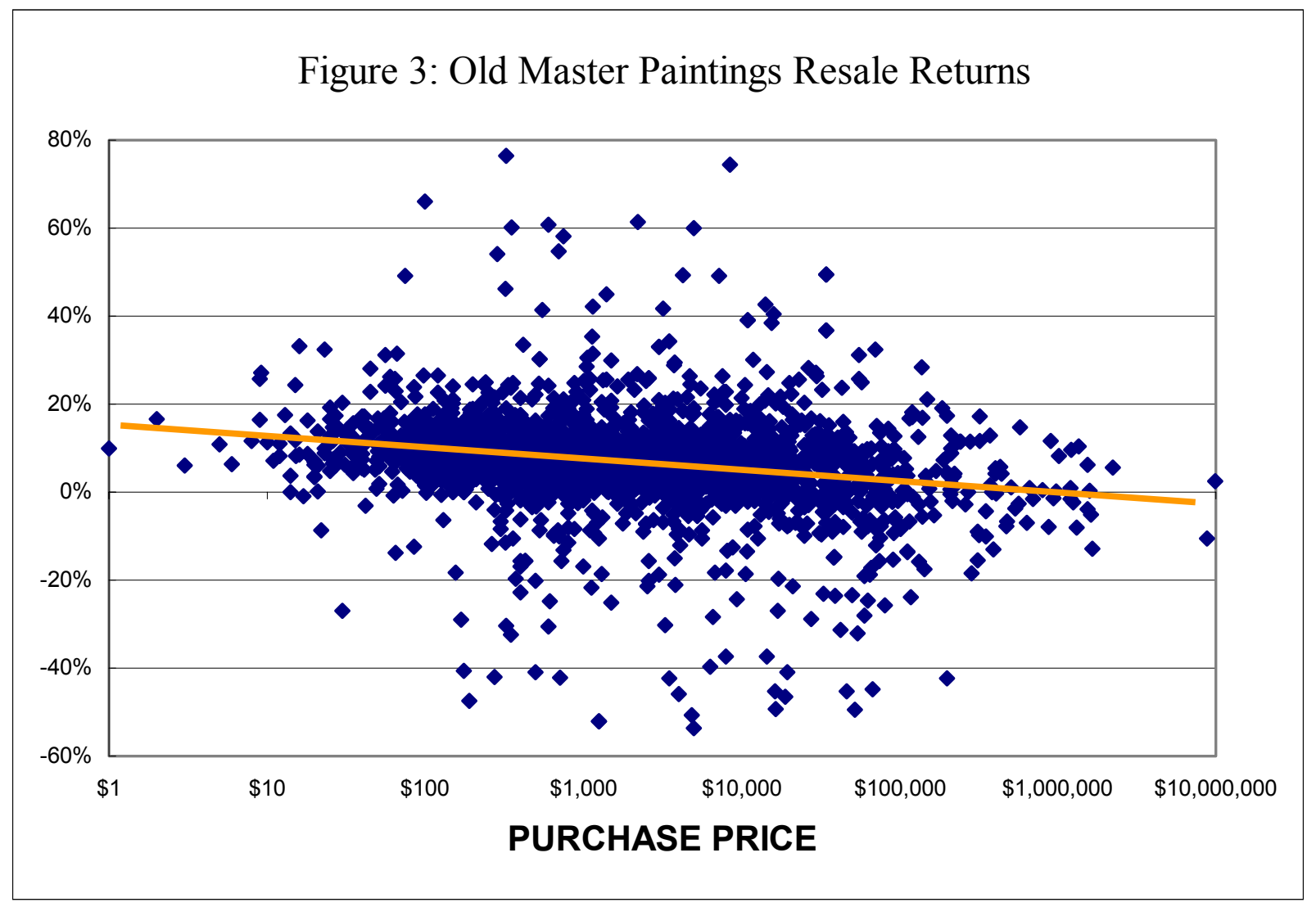


Figure 4: The Relationship between Excess Payment and Future Excess Returns

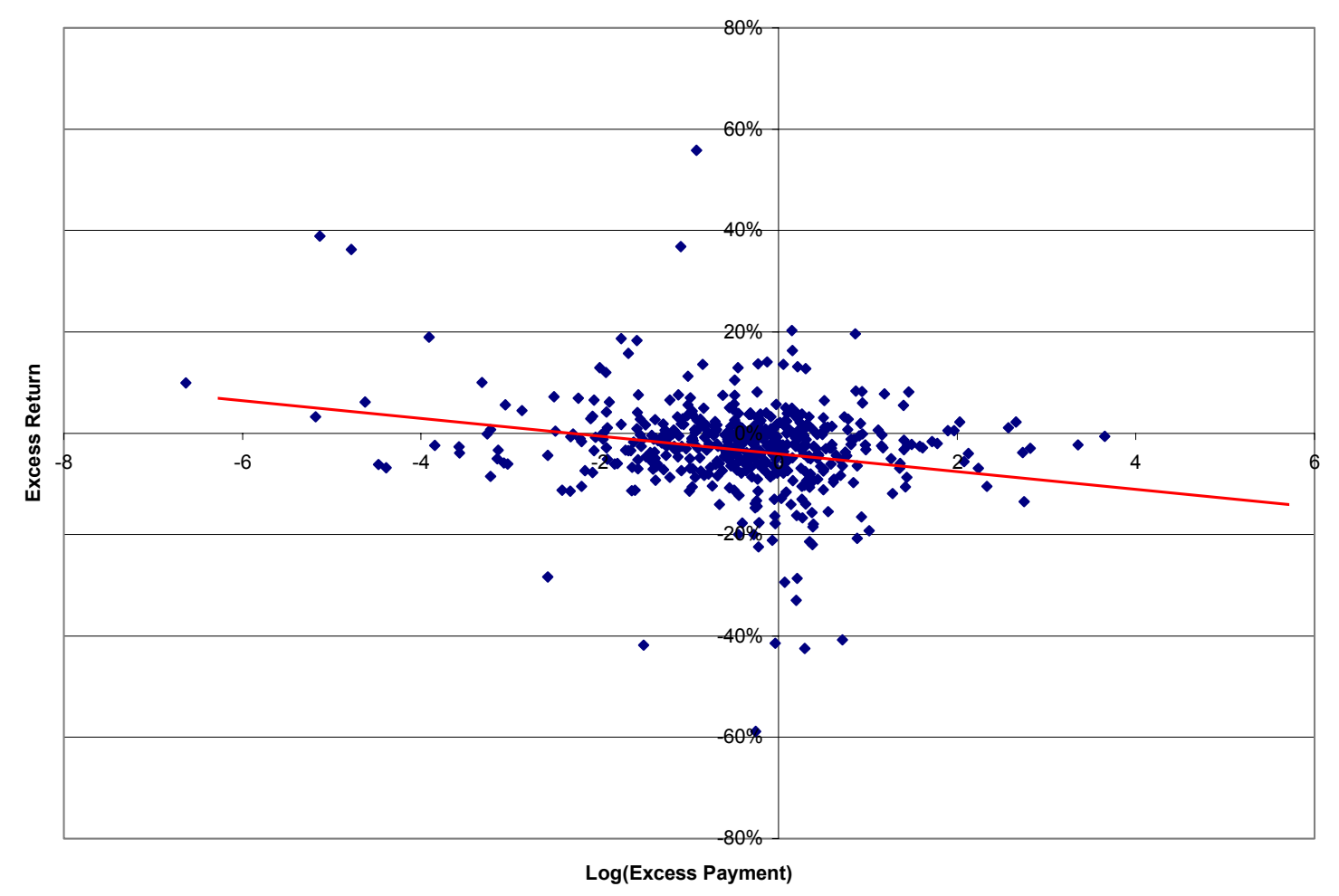

